DOI: 10.17516/1999-494X-0280

УДК $628.33 ; 628.477 .6$

\title{
The Alternative Method of Conditioning Industrial Wastewater Containing Heavy Metals Based on the Hydrothermodynamic Cavitation Technology
}

\author{
Olga G. Dubrovskaya*a, \\ Vladimir A. Kulagina and Yao Limin ${ }^{\mathrm{b}}$ \\ ${ }^{a}$ Siberian Federal University \\ Krasnoyarsk, Russian Federation \\ ${ }^{b}$ Institute of Advanced Technology \\ of the Heilongjiang Academy of Sciences \\ Harbin, China
}

Abstract. This article provides the results of studies of modifying the physicochemical properties of industrial wastewater when treated in a cavitation reactor. The authors performed an analysis of physicochemical changes in the makeup of industrial effluent and defined the efficiency of reducing the content of heavy metal ions under various modes of hydrothermodynamic action. The article also proposes the methods of mathematical modelling for determining the optimal parameters of cavitation treatment of wastewater and reveals the advantages of upgrading the wastewater process equipment with the inclusion of a unit of SC-reactors.

Keywords: industrial wastewater, heavy metals in effluents, cavitation, cavitation technology, recirculating water management, industrial wastewater treatment.

Citation: Dubrovskaya O.G., Kulagin V.A., Limin Yao. The alternative method of conditioning industrial wastewater containing heavy metals based on the hydrothermodynamic cavitation technology, J. Sib. Fed. Univ. Eng. \& Technol., 2020, 13(8), 991-1001. DOI: 10.17516/1999-494X-0280

(C) Siberian Federal University. All rights reserved

This work is licensed under a Creative Commons Attribution-Non Commercial 4.0 International License (CC BY-NC 4.0).

* Corresponding author E-mail address: dubrovskayaolga@mail.ru 


\title{
Альтернативный метод кондиционирования \\ промышленных стоков, содержащих тяжелые металлы, на основе кавитационной технологии
}

\author{
О.Г. Дубровская ${ }^{\mathrm{a}}$, В.А. Кулагин ${ }^{\mathrm{a}}$, Яо Лиминь \\ ${ }^{a}$ Сибирский федеральный университет \\ Российская Федерачия, Красноярск

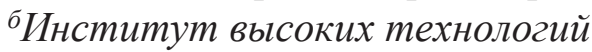 \\ Академии наук провинщчи Хэйлунцзян \\ Китай, Харбин
}

Аннотация. Изложены результаты исследований модифицирования физико-химических свойств промышленной сточной воды при обработке в кавитационном реакторе. Проведен анализ физико-химических изменений компонентного состава промышленного стока и определена эффективность снижения содержания ионов тяжелых металлов при различных режимах гидротермодинамического воздействия. Предложены способы математического моделирования определения оптимальной кавитационной обработки стока, выявлены преимущества модернизации очистного оборудования с включением узла СК-реакторов.

Ключевые слова: промышленные сточные воды, тяжелые металлы в стоке, кавитация, кавитационные технологии, оборотное водопользование, очистка промышленных сточных вод.

Цитирование: Дубровская, О.Г. Альтернативный метод кондиционирования промышленных стоков, содержащих тяжелые металлы, на основе кавитационной технологии / О.Г. Дубровская, В.А. Кулагин, Яо Лиминь // Журн. Сиб. федер. ун-та. Техника и технологии, 2020. 13(8). С. 991-1001. DOI: 10.17516/1999-494X-0280

В настоящее время природоохранное законодательство как Российской Федерации, так и других стран мира предъявляет жесткие требования к методам обработки и утилизации промышленных сточных вод. Данные требования направлены на снижение негативного экологического воздействия промышленных стоков на водные объекты. Современные технологии очистки сточных вод, как отечественные, так и зарубежные, позволяют добиться практически любых степеней очистки, однако применение реагентов, большой объем побочных продуктов очистки - осадков, не позволяют считать имеющиеся технологии экологически безопасными и экономически целесообразными. В большинстве стран к промышленным предприятиям предъявляются требования внедрения оборотного водопользования, соответственно, предприятия пересматривают низкоэффективные стандартные методы кондиционирования промышленного стока и находятся в поиске альтернативных методов очистки сточной воды. Наиболее актуальна проблема очистки стоков, содержащих ионы тяжелых металлов. Как правило, такие сточные воды характерны для промышленных предприятий приборостроения, машиностроения, металлургии, химической и целлюлозно-бумажной отраслей. Тяжелые металлы представляют серьезную экотоксикологическую опасность, их негативное воздействие на физиологию человека было отмечено неоднократно.

На локальных очистных сооружениях вышеперечисленных предприятий чаще всего применяют реагентные методы очистки стока, которые не позволяют достичь эффективности 
очистки до норм сброса в природные водоемы рыбохозяйственного значения либо в централизованную городскую канализацию, но и остаточные концентрации велики для формирования систем оборотного водопользования в качестве очищенной технической воды. Важно, что присутствие ионов тяжелых металлов может влиять на значения $\mathrm{pH}$ и электропроводности раствора, а химические соединения вызывают негативное воздействие на работу инженерных коммуникаций: подвергаясь гидролизу, они могут действовать как сильные кислоты, усиливать вспенивание стока, участвовать в формировании накипей [1]. В связи с этим целесообразно разрабатывать и внедрять в производство альтернативные, безреагентные, инновационные и высокоэффективные методы очистки сточных вод, содержащих ионы тяжелых металлов. К таким методам можно отнести очистку стока, основанную на эффектах гидротермодинамической кавитации.

Цели исследования: выявление закономерностей модифицирования физико-химических параметров воды под воздействием гидротермодинамической кавитации, научное обоснование и разработка безреагентной технологии очистки сточной воды, содержащей ионы тяжелых металлов, с применением методов кавитационного воздействия, происходящего на границах раздела фаз в исследуемой среде, и подбор оптимальных режимов кавитационной обработки сточной воды с целью ее эффективной очистки.

\section{Метод или методология проведения работы}

Методологической базой являются экспериментальные методы термодинамических, кинетических, технологических исследований. В качестве эмпирической базы исследования применены лабораторные и стендовые полупромышленные кавитационные установки. При исследовании эффективности очистки стока использовались стандартные методики оценки качества воды на основании ГОСТ 25150-82, ГОСТ 17.1.1.01-77, ПНДФ 1412.16.1-10, ПНД Ф 14.1:2.105-97, ПНД Ф 14.1:2:4.214-06. Методы VBA-математического моделирования и интерпретации результатов исследования.

\section{Результаты исследования и их обсуждение}

Изменение физико-химических свойств жидкости при гидротермодинамическом кавитационном воздействии основано на высокой концентрации (кумуляции) энергии в очень небольшом объеме газообразной и жидкой среды с последующим ее высвобождением в критически малом временном периоде.

Физические характеристики жидкости оказывают различное влияние на интенсивность кавитационного воздействия, увеличивая или уменьшая скорость кумулятивных струек вблизи твердых границ потока. Особенно сильно это влияние сказывается на последнем этапе схлопывания пузырьков, когда их размеры очень малы. Увеличение вязкости и плотности снижает интенсивность кавитационного воздействия; силы поверхностного натяжения ускоряют коллапс пузырьков; наличие растворенных и нерастворенных газов в жидкости замедляет этот процесс, демпфируя соударение стенок пузырька. Поэтому дегазация жидкости служит одним из способов интенсификации кавитационного воздействия.

Изменение условий проведения технологических процессов также может существенно влиять на интенсивность кавитационного воздействия, а следовательно, и на скорость протека-

$$
-993-
$$


ния соответствующего процесса. Например, снижение температуры и давления насыщенных паров повышает интенсивность кавитационного воздействия. Повышение давления увеличивает скорость кумулятивной струйки при схлопывании пузырька, однако при значительном повышении статического давления трудно получить режимы развитой кавитации.

Время кавитационной обработки также неоднозначно влияет на конечный результат. Не всегда увеличение времени обработки ведет к увеличению технологического эффекта. Поэтому, применяя гидродинамическую кавитацию, необходимо учитывать не только физические свойства жидкостей, но и условия проведения конкретного технологического процесса: давление, температуру, длительность обработки, степень турбулентности потоков, наличие твердых частиц и т.д.

В качестве объекта исследования использовались промышленные сточные воды, основные физико-химические показатели которых получены на основании количественного химического анализа (КХА) сточной воды цехов предприятия приборостроения. Исходные концентрации загрязнителей и требования к остаточным концентрациям очищенного стока с целью его повторного применения приведены в табл. 1.

Как упоминалось выше, в качестве альтернативного метода очистки воды от ионов тяжелых металлов предложен способ гидротермодинамической кавитации. При этом использовали две независимые линии исследований на суперкавитационных реакторах (СК-реактор) разного типа. Такая постановка исследовательской задачи изучения воздействия гидротермодинамической кавитации на сточную воду позволила получить наиболее адекватные результаты по воспроизводимости условий эксперимента, а также дала возможность проведения измерений физических параметров в кавитационной области. Заметим, что физико-химические эффекты идентичны независимо от способа возбуждения кавитации, что, безусловно, важно при решении вопроса о выборе СК-реакторов для определенных технологических решений.

Доказано [1-5], что в условиях гидротермодинамической кавитации протекают сложные физико-химические процессы, классифицируемые следующим образом:

окислительно-восстановительные реакции с участием присутствующих в водной среде органических и неорганических веществ за счет образования в растворе $\mathrm{H}_{2} \mathrm{O}_{2}, \mathrm{O}_{2}, \mathrm{O}_{3}, \mathrm{O}^{\prime}$ и $\mathrm{OH}^{*}$;

Таблица 1. Требования к качеству воды для электронной промышленности РФ ОСТ 11.029.003-80 и США по ASTM D-5127-90

Table 1. Water quality requirements for the electronics industry according to Industrial Standard 11.029.003-80 for the Russian Federation, and according to ASTM D-5127-90 for the USA

\begin{tabular}{|c|c|c|c|c|c|c|c|c|}
\hline \multirow{3}{*}{ Показатель } & \multirow{3}{*}{$\begin{array}{c}\text { Исходная } \\
\text { концентрация, } \\
\text { мг/дм }{ }^{3}\end{array}$} & \multicolumn{7}{|c|}{$\begin{array}{c}\text { Требования к оборотной технической воде } \\
\text { предприятий приборостроения }\end{array}$} \\
\hline & & \multicolumn{3}{|c|}{$\begin{array}{l}\text { ОСТ 11.029.003-80 } \\
\text { КАТЕГОРИИ }\end{array}$} & \multicolumn{4}{|c|}{$\begin{array}{l}\text { ASTM D-5127-90 } \\
\text { КАТЕГОРИИ }\end{array}$} \\
\hline & & $\mathrm{A}$ & Б & B & E-1 & E-2 & E3 & E4 \\
\hline $\mathrm{Cu}$ & 3,94 & 0,002 & 0,002 & 0,003 & 0,001 & 0,001 & 0,002 & 0,5 \\
\hline $\mathrm{Fe}$ & 13,7 & 0,015 & 0,02 & 0,03 & - & - & - & - \\
\hline $\mathrm{Ni}$ & 408,5 & & & & 0,1 & 1 & 2 & 500 \\
\hline $\mathrm{Mn}$ & 0,032 & - & - & - & - & - & - & - \\
\hline
\end{tabular}


цепные реакции в растворе, инициируемые продуктами расщепления присутствующих в растворе примесей;

деструкция макромолекул и инициирование деполимеризации полимерных соединений;

реакции между растворенными газами внутри кавитационных пузырьков.

Так, в качестве обоснования направления очистки от тяжелых металлов был произведен анализ, направленный на получение зависимостей изменения физико-химических параметров водного раствора (стока) при определенных режимах кавитационной обработки. Данные зависимости представлены в табл. 2 и графически отражены на рис. 1.

Для обоснования экологичности метода и экономической целесообразности применения кавитационных реакторов при модернизации технологических схем очистки промышленных стоков был произведен сравнительный анализ по эффективности и энергозатратности традиционного реагентного метода очистки стоков от ионов тяжелых металлов с предлагаемым методом гидротермокавитационной обработки. Результаты сравнения эффективности очистки при различных методах обработки реагентной и гидротермодинамической кавитации представлены в табл. 3 .

Помимо явного преимущества кавитационной технологии при удалении тяжелых металлов из сточной воды, следует обратить внимание и на то, что при реагентном методе для удаления комплекса тяжелых металлов требуется доведение рН среды до значений 10,5-12,0, что, безусловно, влечет за собой повышенное использование реагентов. Образующиеся при этом нерастворимые осадки (как правило, гидроксиды металлов) подвержены длительной седиментации и обводнены на 60-75 \%, как следствие, усложняется технология удаления и обработки подобных осадков сточных вод.

Таблица 2. Изменение физико-химических показателей сточной воды, содержащей ионы тяжелых металлов, при различных режимах кавитационой обработки и последующей релаксации водного раствора (стока)

Table 2. Change in physicochemical parameters of wastewater containing heavy metal ions under various modes of cavitation treatment and subsequent relaxation of the aqueous solution (effluent)

\begin{tabular}{|c|c|c|c|c|c|c|c|}
\hline \multicolumn{2}{|c|}{} & \multicolumn{5}{|c|}{ Режим кавитации } \\
\hline $\begin{array}{c}\text { Показателиментальные данные стоной воды, } \\
\text { содержащей ионы тяжелых } \\
\text { металлов }\end{array}$ & $\begin{array}{c}\text { исходная } \\
\text { сточная вода }\end{array}$ & $\begin{array}{c}3000 \\
\text { об/мин }\end{array}$ & $\begin{array}{c}5000 \\
\text { об/мин }\end{array}$ & $\begin{array}{c}7000 \\
\text { об/мин }\end{array}$ & $\begin{array}{c}10000 \\
\text { об/мин }\end{array}$ & $\begin{array}{c}11000 \\
\text { об/мин }\end{array}$ & $\begin{array}{c}12000 \\
\text { об/мин }\end{array}$ \\
\hline $\mathrm{t}^{\circ} \mathrm{C}$ & 19 & 25 & 30 & 38 & 43 & 42 & 50 \\
\hline $\mathrm{trel}^{\circ} \mathrm{C}$ & 21,5 & 24,5 & 26 & 28,5 & 32 & 30 & 34 \\
\hline $\mathrm{pH}$ & 3,91 & 4,24 & 4,46 & 4,62 & 4,71 & 4,77 & 4,93 \\
\hline $\mathrm{pHrel}$ & 3,83 & 4,26 & 4,49 & 4,68 & 4,68 & 4,86 & 4,97 \\
\hline $\mathrm{OBP}$ & 402 & 383 & 365 & 292 & 270 & 244 & 249 \\
\hline $\mathrm{OBPrel}^{\mathrm{O}}$ & 330 & 342 & 334 & 331 & 316 & 282 & 265 \\
\hline $\mathrm{O}_{2} \mathrm{rel}$ & 7,64 & 8,56 & 8,89 & 9,95 & 10,37 & 9,89 & 8,57 \\
\hline
\end{tabular}



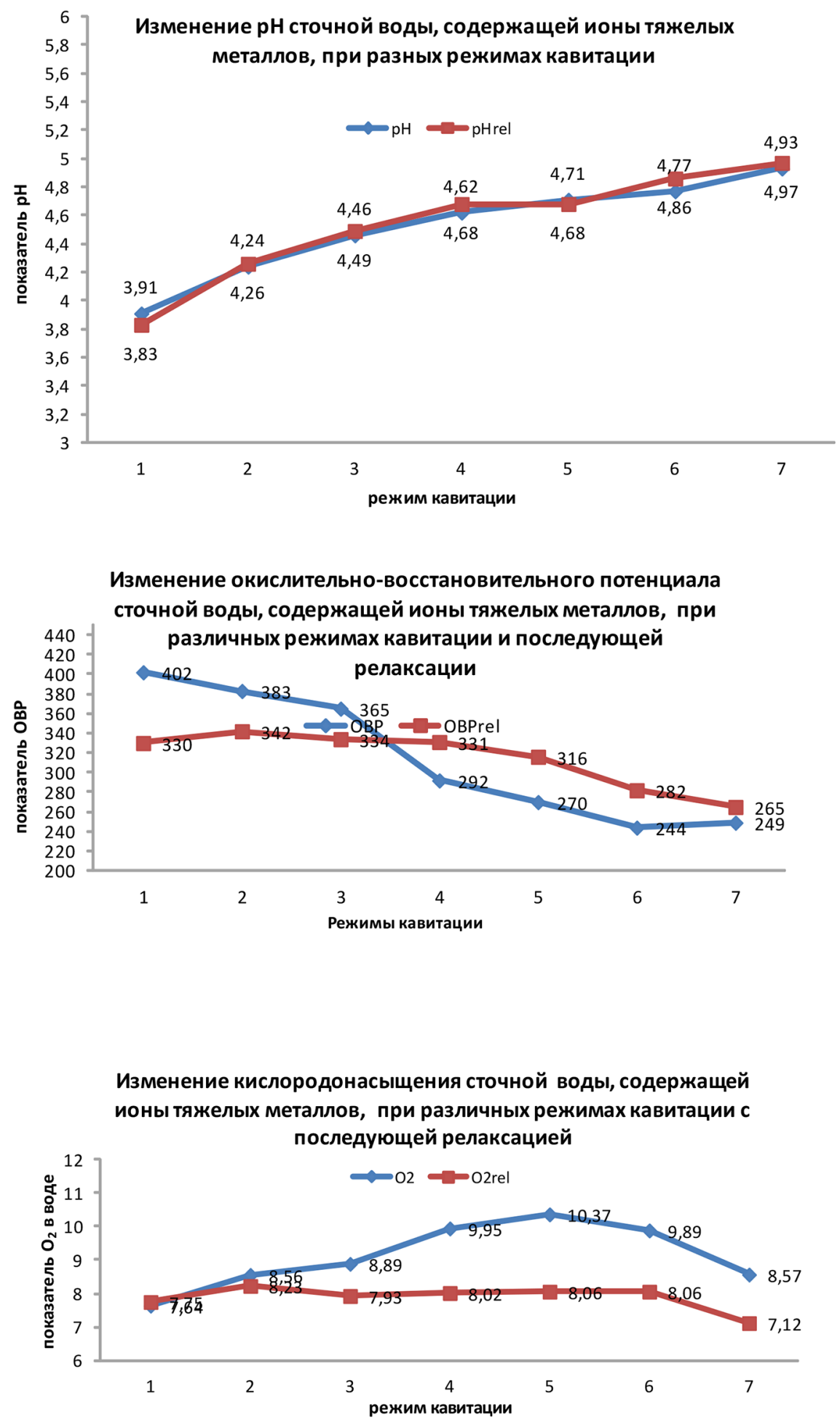

Рис. 1. Графические зависимости изменения физико-химических показателей сточной воды, содержащей ионы тяжелых металлов, от режима кавитационного воздействия

Fig. 1. The diagrams of the dependences of change in the physicochemical parameters of wastewater containing heavy metal ions and the cavitation mode 
Таблица 3. Эффективность удаления тяжелых металлов при различных методах обработки промышленного стока

Table 3. The efficiency of removing heavy metals for different methods of industrial effluent treatment

\begin{tabular}{|c|c|c|c|c|c|c|c|c|}
\hline \multirow{2}{*}{ Ион } & \multirow{2}{*}{$\begin{array}{c}\text { Исходная } \\
\text { концентрация } \\
\text { мг/дм }\end{array}$} & \multicolumn{4}{|c|}{ Концентрация ионов после различных методов обработки стока } \\
\cline { 3 - 9 } & & \multicolumn{4}{|c|}{ Реагентный метод } & \multicolumn{3}{|c|}{10000 об/мин } \\
\cline { 3 - 9 } & 10 мин & 15 мин & 30 мин & Эффект, \% & 10 мин & 15 мин & Эффект, \% \\
\hline $\mathrm{Cu}$ & $\mathbf{3 , 9 4}$ & 3,75 & 3,75 & 3,55 & 9,8 & 2,75 & 1,15 & 70,8 \\
\hline $\mathrm{Fe}$ & $\mathbf{1 3 , 7}$ & 12,66 & 10,7 & 5,6 & 59,12 & 2,66 & 0,64 & 95,3 \\
\hline $\mathrm{Ni}$ & $\mathbf{4 0 8 , 5}$ & 334,9 & 288,07 & 96,9 & 76,27 & 37,25 & 16,25 & 94,54 \\
\hline $\mathrm{Mn}$ & $\mathbf{0 , 0 3 2}$ & 0,022 & 0,022 & 0,022 & 31,25 & 0,017 & 0,017 & 46,8 \\
\hline
\end{tabular}

\section{Сравнительный анализ эффективности очистки промышленного стока от ионов тяжелых металлов разными методами}

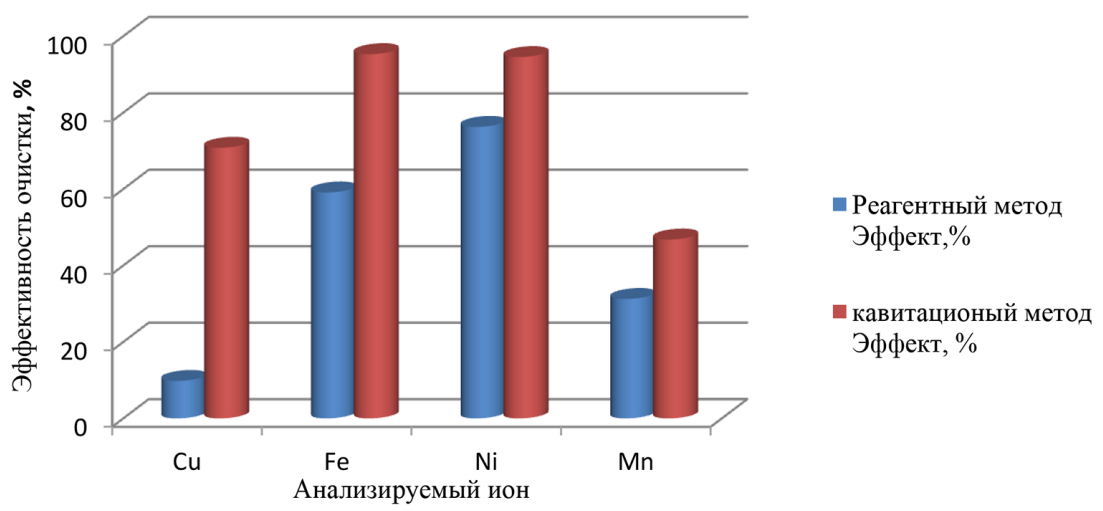

Рис. 2. Эффективность очистки промышленной сточной воды от ионов тяжелых металлов при различных методах обработки

Fig. 2. Efficiency of purification of industrial wastewater from heavy metal ions using different methods of treatment

Анализируя полученные экспериментальные данные, для определения оптимального режима кавитационной обработки промышленного стока выбрали метод математического моделирования с совокупностью методик визуального программирования - VBA, сочетаемого с вычислительными возможностями Excel (рис. 3).

На основании матриц изменения концентрации ионов тяжелых металлов в очищаемой сточной воде и полученных зависимостей от таких факторов, как скорость вращения кавитационной крыльчатки, время обработки, $\mathrm{pH}$ среды, температура среды, получены уравнения регрессии второго порядка. По уравнениям регрессии составлены графические интерпретации в виде поверхностей (рис. 3), что позволяет регулировать процесс безреагентного кондиционирования сточных вод, содержащих тяжелые металлы, и учитывать в дальнейшем техникоэкономические показатели. При обсчете данных использован алгоритм оценки коэффициентов нелинейной регрессионной модели методом наименьших квадратов. Представлен оценочный

$$
-997-
$$




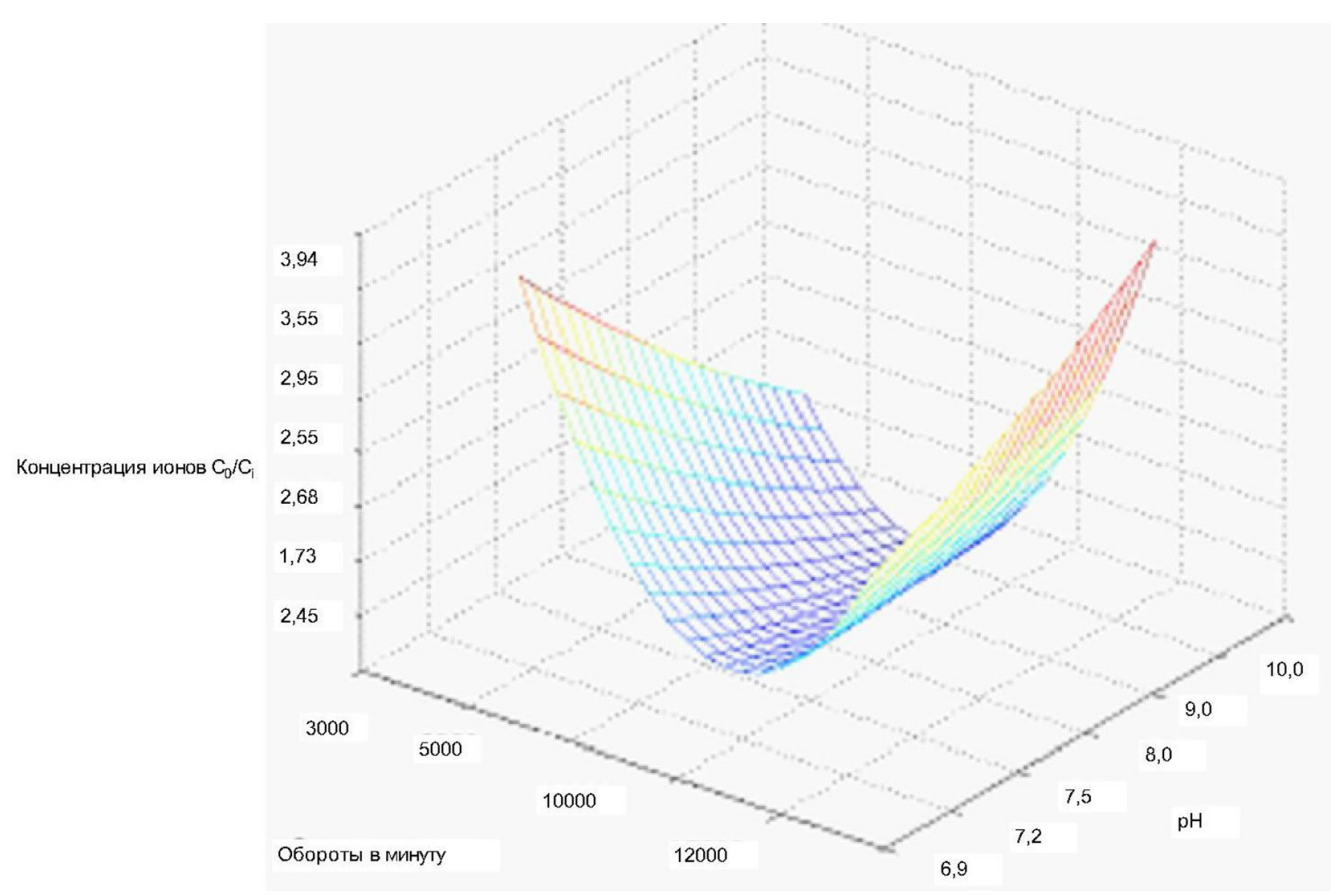

Рис. 3. Регулировочная диаграмма процесса очистки сточных вод, содержащих ионы тяжелых металлов (на примере иона $\mathrm{Cu}^{2+}$ ), методом кавитационной обработки

Fig. 3. The adjustment diagram of the treatment process for wastewater containing heavy metal ions (the case of $\mathrm{Cu}^{2+}$ ion) using cavitation treatment

критерий у1-2 в факторном пространстве следующих параметров: х1; х2; х3. На рис. 3 изображена регулировочная диаграмма очистки стока на примере иона меди.

Интерпретируя результаты математического моделирования и сопоставляя их с фактическими изменениями концентраций ионов тяжелых металлов при различных режимах гидротермодинамической обработки модели сточной воды, можно сделать вывод, что режимом оптимальности для удаления комплекса ионов тяжелых металлов является обработка при 10000 оборотов в минуту в течение 60 с. При более интенсивном режиме кавитационного воздействия наблюдается образование промежуточных продуктов окисления металлов и перекомбинация активных ионов в водной среде с образованием скоагулированных структур в виде гидроксидов металлов, например $\mathrm{Fe}(\mathrm{OH})_{3}$, или же гидроксоаквакомплексов, таких как $\left[\mathrm{Cu}\left(\mathrm{OH}_{2}\right)_{2}(\mathrm{OH})_{2}\right]^{\circ}$, $\left[\mathrm{Zn}\left(\mathrm{OH}_{2}\right)_{2}(\mathrm{OH})_{2}\right]^{\circ},\left[\mathrm{Ni}\left(\mathrm{OH}_{2}\right)_{2}(\mathrm{OH})_{2}\right]^{\circ},\left[\mathrm{Ni}\left(\mathrm{OH}_{2}\right)_{4}(\mathrm{OH})_{2}\right]^{\circ},\left[\mathrm{Fe}\left(\mathrm{OH}_{2}\right)(\mathrm{OH})_{3}\right]^{\circ},\left[\mathrm{Fe}\left(\mathrm{OH}_{2}\right)_{3}(\mathrm{OH})_{3}\right]^{\circ}$. Данные вещества в свою очередь, обладая силой электростатического притяжения за счет изменения заряда комплексона от положительного до отрицательного (при $\mathrm{pH}$ свыше 10.0), выступают коагулянтами. Образующийся скоагулированный осадок в рамках данного исследования также был проанализирован. Определены размеры частиц осадка турбидиметрическим и седиментационным методами анализа. Так, размер хлопьев осадка скоагулированных на гидроксоаквакомплексах $\mathrm{Ni}, \mathrm{Cu}, \mathrm{Zn}$ достигает 130-140 нм, тогда как хлопья осадка, образующиеся и седиментированные на комплексах иона $\mathrm{Fe}^{3+}$, составляют от 24 до 50 мкм.

Все исследования проведены в исследовательской лаборатории Инженерно-строительного института СФУ (ИЛ СМиХАВ) при совместной работе с Институтом высоких технологий 
Академии наук провинции Хэйлунцзян (г. Харбин, КНР) и Международной лабораторией кавитационных технологий Россия-Китай.

Область применения результатов. Результаты данного исследования могут быть применены при модернизации промышленных локальных очистных установок предприятий с внедрением узла кавитационной обработки с целью интенсификации очистки сточной воды от ионов тяжелых металлов.

\section{Заключение}

Данные технические решения позволяют достичь требуемого качества воды для повторного использования. Главными достоинствами предлагаемого безреагентного метода на основе эффектов гидротермодинамической кавитации являются:

1) возможность очистки различного стока со значительным колебанием количественного содержания загрязняющих веществ;

2) возможность использования предлагаемой технологии при модернизации существующего оборудования. СК-генераторы легко встраиваются в существующие сооружения, например аккумулирующие емкости, без значительного изменения их конструкции;

3) возможность автоматизировать процесс очистки;

4) снижение эксплуатационных экономических затрат;

5) снижение негативного воздействия на водные объекты при сбросе промышленных сточных вод.

Введение блока кавитационной обработки для интенсификации очистки промышленного стока и кондиционирования технической воды позволит сформировать замкнутый оборотный цикл водопользования и значительно повысить экологическую устойчивость региона присутствия промышленных комплексов.

\section{Благодарности / Acknowledgments}

Исследование выполнено при финансовой поддержке РФФИ и Правительства Красноярского края в рамках научных проектов № 18-41-242008 «Теплофизические и гидродинамические особенности кинетики смесеобразования при иммобилизации радиоактивных отходов в цементную матрицу с использованием эффектов кавитации» и 18-41-242004 «Теоретические основы кондиционирования вод питьевого назначения на базе эффектов гидродинамической кавитации».

The reported study was funded by RFBR and the government of Krasnoyarsk region according to the research projects no. 18-41-242008 Thermo physical and hydrodynamic features of the kinetics of mixture formation upon immobilization of radioactive waste in cement matrix using the effects of cavitation \& 18-41-242004 Theoretical Foundations of potable water conditioning on the basis of the effects of hydrodynamic cavitation.

\section{Список литературы / References}

[1] Kurilina T.A., Dubrovskaya O.G., Kulagin V.A., Matyushenko A.I., Bobrik A.G. The prospects of utilizing the modified sorption material to intensify purification of waste water from electroplating production. J. Sib. Fed. Univ. Eng. technol., 2019, 12(2), 182-191.

$$
-999-
$$


[2] Дубровская О.Г., Кулагин В.А. Безреагентная очистка промышленных сточных вод, содержащих тяжелые металлы на основе технологии гидротермодинамической кавитации, Журнал Сибирского федерального университета. Техника и технологии. 2019, 12(4), 460-467 [Dubrovskaya O.G., Kulagin V.A., Reagent-free treatment of industrial wastewater containing heavy metals based on hydrothermodynamic cavitation technology, J. Sib. Fed. Univ. Eng. technol., 2019, 12(4), 460-467 (in Russian)].

[3] Дубровская О.Г., Приймак Л.В., Андруняк И.В. Ресурсосберегающие технологии обезвреживания и утилизации отходов предприятий теплоэнергетического комплекса Красноярского края. Красноярск: Сиб. федер. ун-т, 2014. 164 с. [Dubrovskaya O.G., Priymak L.V., Andrunayk I.V. Resource-saving technologies for neutralization and disposal of waste from enterprises of the heat and power complex of the Krasnoyarsk Territory Krasnoayrsk, Sib. Fed. Univ., 2014. 164 p. (in Russian)]

[4] Дубровская О.Г., Евстигнеев В.В., Кулагин В.А. Кондиционирование сточных вод энергетических систем и комплексов. Журнал Сибирского федерального университета. Техника и технологии. 2011, 6(4), 665-675. [Dubrovskaya O.G., Evstigneev V.V., Kulagin V.A. Waste water conditioning of energy systems and complexes. J. Sib. Fed. Univ. Eng. technol., 2011, 6(4), 665-675 (in Russian)]

[5] Эльдарзаде Э.А. Использование очищенного промышленного и ливневого стока как альтернативного источника водопользования предприятия. Строительство и Архитектура - формирование среды жизнедеятельности, 2016, 122-123. [Eldarzade E.A. Use of purified industrial and storm runoff as an alternative source of water use for an enterprise, Construction and Architecture - formation of a living environment, 2016, 122-123 (in Russian)]

[6] Куликова Н.И., Ножевникова А.Н. Очистка муниципальных сточных вод с повторным использованием воды и обработанных осадков: теория и практика. М.: Логос, 2014. 400 c. [Kulikova N.I., Nozhevnikova A.N. Municipal Wastewater Treatment with Reuse of Water and Recycled Sludge: Theory and Practice. Moscow: Logos 2014. 400 p. (in Russian)]

[7] Дубровская О.Г., Кулагин В.А., Сапожникова Е.С. Современные компоновки технологических схем очистки сточных вод с использованием кавитационной технологии. Журнал Сибирского федерального университета. Техника и технологии. 2015, 8(2), 217-223. [Dubrovskaya O.G., Kulagin V.A., Sapozhnikova E.S. Modern layouts of technological schemes for wastewater treatment using cavitation technology. J. Sib. Fed. Univ. Eng. technol., 2015, 8(2), 217-223 (in Russian)]

[8] Дубровская О. Г., Кулагин В.А., Сапожникова Е.С., Ли Ф.Ч., Ли Ц., Чжэн Ч.Ин Математическое моделирование кавитационных процессов при кондиционировании промышленных сточных вод. Журнал Сибирского федерального университета. Техника и технологии. 2015, 8(3), 369-376. [Dubrovskaya O.G., Kulagin V.A., Sapozhnikova E.S., Li F. Ch., Li Zh., Chzen Ch. In. Mathematical modeling of cavitation processes in the conditioning of industrial wastewater. $J$. Sib. Fed. Univ. Eng. technol., 2015, 8(3), 369-376 (in Russian)]

[9] Гимаева А.Р., Валинурова Э.Р., Игдавлетова Д.К., Кудашева Ф.Х. Сорбция ионов тяжелых металлов из воды активированными углеродными адсорбентами. Сорбиионные и хроматографические проиессы. 2011, 11(3), 350-356. [Gimaeva A.R., Valinurova E.R., Igdavletova D.K., Kudasheva F.Kh. Sorption of heavy metal ions from water by activated carbon adsorbents. Sorption and chromatographic processes, 2011, 11(3), 350-356 (in Russian)]

$$
-1000-
$$


[10]Зыкова И.В., Лысенко И.В., Панов В.П. Адсорбция ионов меди керамической крошкой из бинарных и многокомпонентных растворов. Известия вузов. Химия и химическая технология. 2004, 47(9), 151-167. [Zykova I.V., Lysenko I.V., Panov V.P. Adsorption of copper ions by ceramic chips from binary and multicomponent solutions. Izvestiya vuzov. Chemistry and chemical technology. 2004, 47(9), 151-167 (in Russian)]

[11] Цветкова А.Д., Акаев О.П. Исследование процесса адсорбции ионов меди на модифицированном диоксиде кремния. Вестник КГУ им. Н.А. Некрасова. 2011, 2, 27-30. [Tsvetkova A.D., Akaev O.P. Study of the process of adsorption of copper ions on modified silicon dioxide. Bulletin of KSU named after N.A. Nekrasov. 2011, 2, 27-30 (in Russian)]

[12]Мухин В.М., Тарасов А.В., Клушин В.Н. Активные угли России. М.: Металлургия, 2000. 352 c. [Mukhin V.M., Tarasov A.V., Klushin V.N. Active coals of Russia. Moscow: Metallurgy. 2000, 352 p. (in Russian)]

[13]Тимофеев К.Л., Усольцев А.В., Краюхин С.А., Мальцев Г.И. Кинетика сорбции ионов индия, железа и цинка слабокислотными катионитами. Сорбционные и хроматографические проиессы. 2015, 15(5), 720-729. [Timofeev K.L., Usoltsev A.V., Krayukhin S.A., Maltsev G.I. Kinetics of sorption of indium, iron and zinc ions by weakly acidic cation exchangers, Sorption and chromatographic processes. 2015, 1 (5), 720-729 (in Russian)]

[14] Филатова Е.Г., Помазкина О.И., Дударев В.И., Шевелева Н.Н. Комплексная технология извлечения ионов никеля и меди из промышленных сточных вод. Водоочистка. 2012, 12, 20-25. [Filatova E.G., Pomazkina O.I., Dudarev V.I., Sheveleva N.N. Integrated technology for the extraction of nickel and copper ions from industrial wastewater. Water treatment. 2012, 12, 20 -25 (in Russian)]

[15]Wang Ji-Zhong, Sheng-Rong Li, Bao-Lin Liu, Jing-Gui Tong Removal of heavy metals from wastewater from using natural minerals. Bull Mineral Petrol Geochem. 2005, 24(2), 159-164.

[16]Svilovi'c S., Ruši'c D., Stipiši'c R. Modeling batch kinetics of copper ions sorption using synthetic zeolite NaX. Journal of Hazardous Materials. 2009, 170, 941-947.

[17]Demirbas Ayhan. Heavy metal adsorption onto agrobased waste materials. Journal of Hazardous Materials. 2008, 157(2-3), 220-229.

[18]Lokendra S. Thakur, Mukesh Parmar. Adsorption of heavy metal from synthetic waste water by tea waste adsorbent. International Journal of Chemical and Physical Sciences. 2013, 2(6), 6-19.

[19]Tumin Najua D., Luqman Chuah A., Zawani Z., Abdul Rashid S. Adsorption of copper from aqueous solution by Elais Guineensis kernel activated carbon. Journal of Engineering Science and Technology. 2008, 3(2), 180-189. 